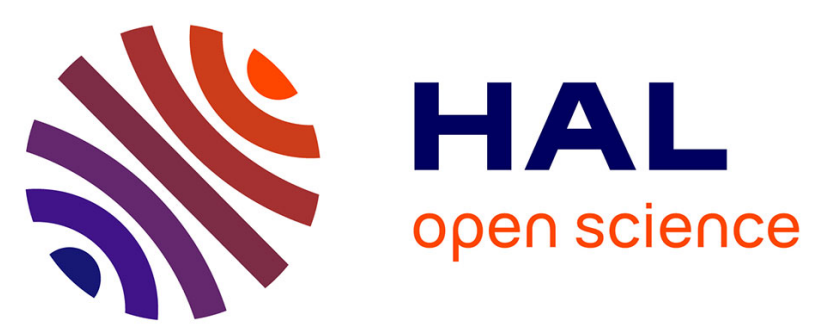

\title{
Dissociative Adsorption of Nitric Acid at the Surface of Amorphous Solid Water Revealed by X-ray Absorption Spectroscopy
}

\author{
G. Marcotte, P. Ayotte, A. Bendounan, F. Sirotti, C. Laffon, P. Parent
}

\section{To cite this version:}

G. Marcotte, P. Ayotte, A. Bendounan, F. Sirotti, C. Laffon, et al.. Dissociative Adsorption of Nitric Acid at the Surface of Amorphous Solid Water Revealed by X-ray Absorption Spectroscopy. Journal of Physical Chemistry Letters, 2013, 4 (16), pp.2643-2648. 10.1021/jz401310j . hal-00914743

\author{
HAL Id: hal-00914743 \\ https://hal.science/hal-00914743
}

Submitted on 21 Apr 2020

HAL is a multi-disciplinary open access archive for the deposit and dissemination of scientific research documents, whether they are published or not. The documents may come from teaching and research institutions in France or abroad, or from public or private research centers.
L'archive ouverte pluridisciplinaire HAL, est destinée au dépôt et à la diffusion de documents scientifiques de niveau recherche, publiés ou non, émanant des établissements d'enseignement et de recherche français ou étrangers, des laboratoires publics ou privés.

\section{(c)(1)}

Distributed under a Creative Commons Attribution| 4.0 International License 


\title{
Dissociative Adsorption of Nitric Acid at the Surface of Amorphous Solid Water Revealed by X-ray Absorption Spectroscopy
}

\author{
and Philippe Parent* ${ }^{* \perp}$ \\ †Université Pierre et Marie Curie, LCPMR UMR 7614, 75005 Paris, France
${ }^{\ddagger}$ Université de Sherbrooke, 2500 Boulevard de l’Université, Sherbrooke, Canada J1K 2R1
${ }^{\S}$ Synchrotron SOLEIL, L’Orme des Merisiers, Saint-Aubin, 91192 Gif-sur-Yvette, France
${ }^{\perp}$ Aix-Marseille Université, CNRS, CINaM UMR 7325, 13288 Marseille, France
}

Guillaume Marcotte, ${ }^{\dagger \neq}$ Patrick Ayotte, ${ }^{*}+\underset{ }{\ddagger}$ Azzedine Bendounan, ${ }^{\S}$ Fausto Sirotti, ${ }^{\S}$ Carine Laffon, ${ }^{\perp}$

Supporting Information

\begin{abstract}
A spectral feature unique to the molecularly adsorbed state of $\mathrm{HNO}_{3}$ is found in X-ray absorption spectroscopy. This distinctive signature reveals the extent to which nitric acid is ionically dissociated upon its adsorption on amorphous solid water (ASW) at low coverage and low temperature. Thermal annealing induces irreversible proton transfer from $\mathrm{HNO}_{3(\mathrm{ads})}$, demonstrating that it is metastable with respect to ionic dissociation below $100 \mathrm{~K}$ at the surface of ASW. The slight decrease in ionic dissociation propensity reported for nitric acid at liquid water surfaces thus appears to be overwhelmed by the strong exothermicity of this reaction as its entropic inhibition becomes increasingly suppressed the lower the temperature. These findings may be relevant for atmospheric chemistry processes involving nitric acid, which should thus, according to thermodynamic considerations, be expected to behave as a strong acid at the surface of supercooled aerosols and of the quasi-liquid layer.
\end{abstract}

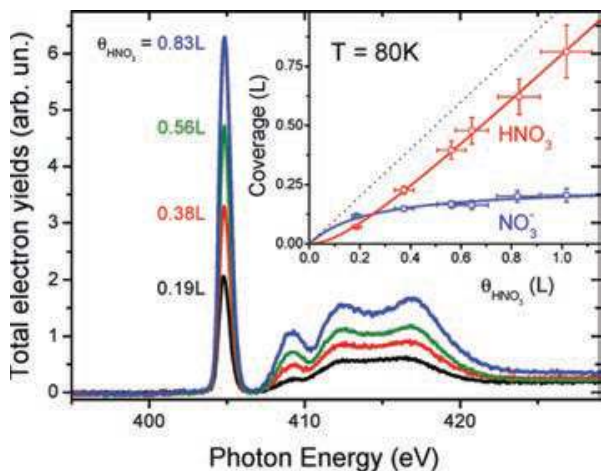

SECTION: Environmental and Atmospheric Chemistry, Aerosol Processes, Geochemistry, and Astrochemistry

$\mathrm{G}$ iven its major role in a plethora of environmental processes, the dissociative adsorption and acid-base chemistry of $\mathrm{HNO}_{3}$ at aqueous interfaces continues to attract tremendous interest from both theoretical ${ }^{1-7}$ and experimental perspectives. $^{7-14}$ Indeed, our understanding of several important atmospheric chemistry processes hinges on a quantitative description of the factors and parameters that control whether $\mathrm{HNO}_{3}$ exists in its molecular or its dissociated form at the surface of atmospheric aerosols and of ice. For instance, this would impact our interpretation of the formation, stability, and reactivity of nitrates in urban particulate matter, ${ }^{15-19}$ the atmospheric reactive nitrogen budget, ${ }^{20-24}$ the intriguing $\mathrm{NO}_{x}$ photochemical fluxes from snowpacks, ${ }^{20,25,26}$ and the formation and lifetime of cirrus clouds. $^{27-31}$

At the surface of nitric acid solutions, the ionic dissociation of $\mathrm{HNO}_{3}$ was reported to be inhibited compared to the bulk, ${ }^{1-11}$ an effect that was attributed to incomplete solvation at aqueous interfaces. Generally speaking, the stability of molecular nitric acid with respect to ionic dissociation appears to be promoted by increasing temperatures ${ }^{9,32}$ and by higher $\mathrm{HNO}_{3}$ concentrations, ${ }^{9-11}$ both in the bulk of nitric acid solutions ${ }^{11,32}$ as well as at their surface. ${ }^{10,11}$ However, the extent of this weaker acidity is still being debated because it varies with these parameters as well as with the inherent surface specificity of the technique. ${ }^{8,10}$ While the magnitude of this effect differs significantly between these various reports, they agree, nonetheless, that nitric acid appears to behave as a weaker acid at the surface of liquid water than in the bulk. ${ }^{8,10}$ Molecular modeling and numerical simulations have also contributed greatly at providing a molecular-level understanding of the hydrogen-bond structure and dynamics that control ionic dissociation of $\mathrm{HNO}_{3}$ at aqueous interfaces, yielding invaluable mechanistic information. ${ }^{1-4,33}$

Despite these important advances, great uncertainty still shrouds the extent of ionic dissociation at the surface of supercooled liquid and ice aerosols. ${ }^{34}$ Under the colder environments of the troposphere and lower stratosphere, it is still an open question as to whether the slightly weaker acidity of nitric acid at aqueous surfaces ${ }^{10,11}$ will be overwhelmed by the strong decrease in $\mathrm{p} K_{\mathrm{a}}$ of nitric acid solutions in the supercooled regime ${ }^{32}$ or whether molecular nitric acid could become trapped in a metastable molecularly adsorbed state at the surface of ice particles or atmospheric aerosols. Investigating the chemical state of $\mathrm{HNO}_{3}$ at the surface of supercooled solutions or ice therefore requires surface-sensitive spectroscopic tools and/or appropriate sample preparation methods. Only by reaching cryogenic temperatures (i.e., in the 
$70-135 \mathrm{~K}$ range by Devlin et al. ${ }^{14}$ and the $130-150 \mathrm{~K}$ range by Pursell et al. ${ }^{13}$ ) has molecular nitric acid been observed at the surface of ice. Unfortunately, both studies relied on FTIR spectroscopy, which lacks the surface specificity and sensitivity to detect submonolayer coverages of $\mathrm{HNO}_{3}$ adsorbed onto ice. Accordingly, their sample preparation methodology and their experimental conditions suggest that they observed molecular nitric acid as a result of multilayer condensation ${ }^{13}$ or in the form of nitric acid nanocrystals at the surface of ice. ${ }^{14}$ Recently, Krepelova et al. $^{35}$ used near-edge X-ray absorption fine structure (NEXAFS) to study the adsorption of $\mathrm{HNO}_{3}$ onto ice at $230 \mathrm{~K}$, relying, however, on heterogeneous $\mathrm{NO}_{2}$ hydrolysis as a source of $\mathrm{HNO}_{3}$. They reported the observation of nitrates dissolved within a $1.1 \mathrm{~nm}$ thick supercooled nitric acid solution layer at the ice surface, but they could not observe molecular $\mathrm{HNO}_{3}$ under these conditions. Most recently, some of us reported the observation of molecularly adsorbed $\mathrm{HNO}_{3}$ onto ASW at $45 \mathrm{~K}$ using molecular beam deposition and reflection absorption infrared spectroscopy (RAIRS). ${ }^{12}$

It this Letter, we report a study of the adsorption of $\mathrm{HNO}_{3}$ onto amorphous solid water (ASW) at cryogenic temperatures using NEXAFS in an attempt to (1) prepare the molecular state of nitric acid at the surface of ice, (2) probe and characterize its electronic structure, (3) investigate its saturation coverage for dissociative adsorption on ice, and (4) study its thermal stability. Dense ASW is used as a model for the surface of deeply supercooled liquid water ${ }^{36,37}$ and nitric acid solutions. $\mathrm{HNO}_{3}$ adsorption is performed at cryogenic temperatures (23$80 \mathrm{~K})$ in order to suppress diffusive uptake into the bulk, thereby eliminating uncertainties of previous studies regarding the partitioning between the surface and bulk of nitrate ions $^{38-40}$ and protons, ${ }^{41-44}$ which are still subject to much debate. We report very distinctive NEXAFS spectral features that allow straightforward quantification of the partitioning between $\mathrm{HNO}_{3}$ and $\mathrm{NO}_{3}{ }^{-}$on ASW to be performed as a function of nitric acid exposure $(0.19-1.0 \mathrm{~L})$ and annealing temperature $(23-150 \mathrm{~K})$. The sensitivity and the combined surface specificity of NEXAFS and vapor deposition at cryogenic temperature allow the demonstration that nitric acid dissociates at temperatures as low as $23 \mathrm{~K}$ and that the molecularly adsorbed state of $\mathrm{HNO}_{3}$ is metastable with respect to ionic dissociation.

Figure 1 presents the NEXAFS spectra of a $3 \% \mathrm{HNO}_{3}$ mole fraction $\mathrm{HNO}_{3} / \mathrm{H}_{2} \mathrm{O}$ mixture at $80 \mathrm{~K}$ (top panels, a and $\mathrm{b}$, providing the spectral signature of the dissociated form of nitric acid, $\left.\mathrm{NO}_{3}^{-}{ }_{(\mathrm{aq}}\right)^{35,45}$ and of "neat" solid $\mathrm{HNO}_{3}$ at $80 \mathrm{~K}^{12,46}$ (bottom panels, $\mathrm{c}$ and $\mathrm{d}$, providing the spectral signature for the "molecular" form of nitric acid, $\mathrm{HNO}_{3(\mathrm{~s})}$ ). NEXAFS spectra were acquired at the $\mathrm{N}$ K-edge (left panels, a and c; over the 395-430 eV range) and at the O K-edge (right panels, b and d; over the 525-570 eV range). Detailed descriptions of the sample preparation protocols and of the precautions taken in selecting appropriate spectroscopic analysis conditions are provided in the Supporting Information (SI). Spectral features are assigned based on their similarities to the NEXAFS spectra of inorganic nitrate salts ${ }^{45,47-49}$ as well as those of nitrates on ice $^{35}$ and based on electronic structure calculations of the molecular orbitals energies and symmetries for $\mathrm{NO}_{3}^{-}(\mathrm{g})$ and $\mathrm{HNO}_{3(\mathrm{~g})}$ (data not shown). ${ }^{50}$

At the N K-edge (Figure 1a), the NEXAFS spectrum of the $3 \% \mathrm{HNO}_{3}$ mole fraction $\mathrm{HNO}_{3} / \mathrm{H}_{2} \mathrm{O}$ mixture at $80 \mathrm{~K}$ presents a sharp feature peaked at $404.7 \mathrm{eV}$ corresponding to transitions to the $2 \mathrm{a}_{2}{ }^{\prime \prime}\left(\pi^{*}\right)$ LUMO orbital of $\mathrm{NO}_{3}^{-}{ }_{(\mathrm{aq})}$. A slight inflection

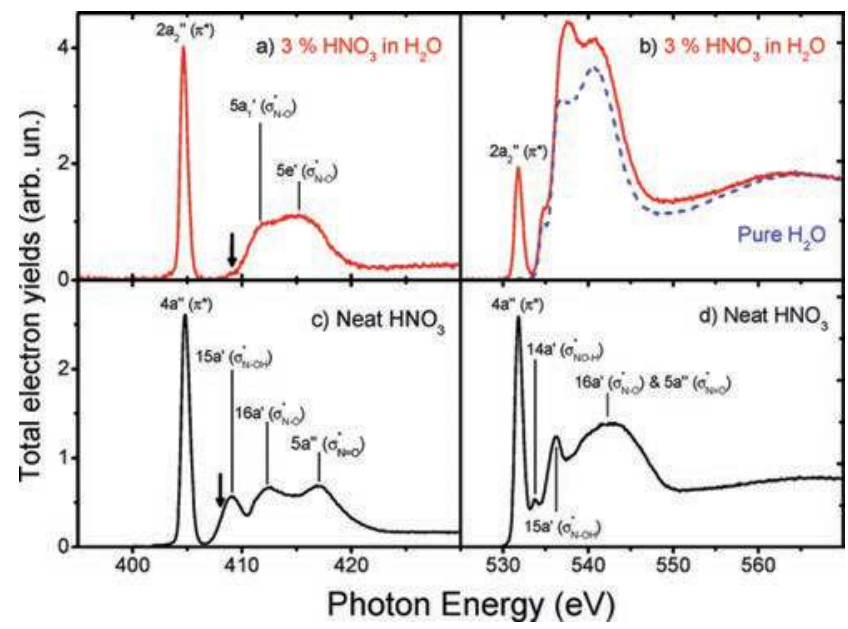

Figure 1. NEXAFS spectra for $\mathrm{NO}_{3}{ }^{-}$(aq) $\left(3 \%\right.$ mole fraction of $\mathrm{HNO}_{3}$ in $\mathrm{H}_{2} \mathrm{O}$ ) at the nitrogen $\mathrm{K}$-edge (a) and at the oxygen $\mathrm{K}$-edge (b) and that for molecular $\mathrm{HNO}_{3(s)}$ at the nitrogen K-edge (c) and at the oxygen K-edge (d). Ionization potentials at the $\mathrm{N} \mathrm{K}$-edge were located by XPS and are reported by arrows in panels (a) and (c). Molecular orbitals assignment for $\mathrm{NO}_{3}{ }^{-}$and $\mathrm{HNO}_{3}$ is proposed based on ab initio calculations and on the literature. ${ }^{35,47-49}$ At the oxygen K-edge, the NEXAFS spectrum for a $3 \%$ mole fraction of $\mathrm{HNO}_{3}$ in water is dominated by the aqueous component of the mixture, which can be approximated by the NEXAFS spectrum of dense ASW (dashed blue line).

in the baseline is observed at around $409 \mathrm{eV}$, which coincides with the $\mathrm{N}(1 \mathrm{~s})$ ionization potential of the nitrate anion dissolved in condensed water. This was confirmed by separate XPS measurements (arrow in Figure 1a), which agree with previous XPS studies of nitrates in liquid water. ${ }^{51}$ Just above this threshold, a broad featureless band spans the range from 410 to $420 \mathrm{eV}$ that displays contributions arising from transitions to the $5 \mathrm{a}_{1}{ }^{\prime}\left(\sigma^{*}{ }_{\mathrm{N}-\mathrm{O}}\right)$ and doubly degenerate $5 \mathrm{e}^{\prime}$ $\left(\sigma^{*}{ }_{\mathrm{N}-\mathrm{O}}\right)$ orbitals of $\mathrm{NO}_{3}{ }_{(\mathrm{aq})}$. This spectrum is in very good agreement with recent NEXAFS data for nitrates on ice, resulting from the heterogeneous hydrolysis of $\mathrm{NO}_{2}$ on ice at $230 \mathrm{~K}$, reported by Krepelova et al. ${ }^{35}$

The NEXAFS O K-edge spectrum of the $3 \% \mathrm{HNO}_{3}$ mole fraction $\mathrm{HNO}_{3} / \mathrm{H}_{2} \mathrm{O}$ mixture at $80 \mathrm{~K}$ (red line, Figure $1 \mathrm{~b}$ ) does display features due to $\mathrm{NO}_{3}{ }^{-}$(aq); however, it is overwhelmed by a large contribution from the $\mathrm{H}_{2} \mathrm{O}$ component of the aqueous mixture. This latter can be gleaned from the NEXAFS spectrum of vapor-deposited ASW (dashed blue line, Figure 1b). ${ }^{52}$ The only distinctively resolved feature that can thus be confidently attributed to nitrate anions in the binary mixture lies at 531.8 $\mathrm{eV}$ and is assigned to transitions to the $2 \mathrm{a}_{2}{ }^{\prime \prime}\left(\pi^{*}\right)$ LUMO orbital of $\mathrm{NO}_{3}^{-}{ }_{(\text {aq) }}$.

The N K-edge NEXAFS spectrum of $\mathrm{HNO}_{3(\mathrm{~s})}$ (Figure 1c) features four major peaks; the sharp and intense feature at $404.8 \mathrm{eV}$ is assigned to transitions to the $4 \mathrm{a}^{\prime \prime}\left(\pi^{*}\right)$ LUMO orbital of $\mathrm{HNO}_{3}$, while the three broader bands centered near 409.0, 412.3, and $417.0 \mathrm{eV}$ are assigned to transitions to the $15 \mathrm{a}^{\prime}\left(\sigma_{\mathrm{N}-\mathrm{OH}}^{*}\right), 16 \mathrm{a}^{\prime}\left(\sigma^{*}{ }_{\mathrm{N}-\mathrm{O}}\right)$, and $5 \mathrm{a}^{\prime \prime}\left(\sigma_{\mathrm{N}=\mathrm{O}}^{*}\right)$ molecular orbitals, respectively. The $\mathrm{HNO}_{3} \mathrm{~N}$ K-edge ionization potential was located at $408 \mathrm{eV}$ by separate XPS measurements (arrow in Figure 1c).

Figure 1d displays the NEXAFS spectrum of $\mathrm{HNO}_{3(\mathrm{~s})}$ at the $\mathrm{O}$ K-edge. The sharp and tall spectral feature at $531.8 \mathrm{eV}$ is assigned to transitions to the $4 \mathrm{a}^{\prime \prime}\left(\pi^{*}\right)$ LUMO orbital of $\mathrm{HNO}_{3}$. The small peaks at 533.7 and $536.2 \mathrm{eV}$ are assigned to 
transitions to the $14 \mathrm{a}^{\prime}\left(\sigma_{\mathrm{NO}-\mathrm{H}}^{*}\right)$ and $15 \mathrm{a}^{\prime}\left(\sigma_{\mathrm{N}-\mathrm{OH}}\right)$ orbitals, respectively, while the broad band at $542.5 \mathrm{eV}$ is attributed to transitions to the strongly overlapping $16 \mathrm{a}^{\prime}$ and $5 \mathrm{a}^{\prime \prime}\left(\sigma^{*}{ }_{\mathrm{N}-\mathrm{O}}\right.$ and $\sigma_{\mathrm{N}=\mathrm{O}}^{*}$ ) molecular orbitals of $\mathrm{HNO}_{3}$, respectively.

While the NEXAFS spectra of nitrates on ice have been reported previously ${ }^{35}$ and their assignment is well-established, ${ }^{47-49}$ we believe that, to the best of our knowledge, this is the first report of the NEXAFS spectrum of molecular nitric acid in the solid phase. Our proposed assignment is based on those of NEXAFS spectra for nitrates salts as well as on electronic structure calculations for $\mathrm{HNO}_{3(\mathrm{~g})}$ and $\mathrm{NO}_{3}{ }^{-}$(g) ; the large pre-edge features at $404.8(531.8) \mathrm{eV}$ in the NEXAFS spectra at the $\mathrm{N}(\mathrm{O}) \mathrm{K}$-edge are assigned to transitions to the $4 a^{\prime \prime}\left(\pi^{*}\right)$ LUMO orbital of molecular nitric acid, while transitions to the $14 \mathrm{a}^{\prime}\left(\sigma^{*}{ }_{\mathrm{NO}-\mathrm{H}}\right)$ orbitals, located at $533.7 \mathrm{eV}$ in the NEXAFS spectra at the $\mathrm{O}$ K-edge, are characteristic of the hydroxyl group of $\mathrm{HNO}_{3}$. The bands at $409.0(536.2) \mathrm{eV}$ at the $\mathrm{N}(\mathrm{O})$ K-edge are assigned to transitions to the $15 \mathrm{a}^{\prime}$ $\left(\sigma^{*}{ }_{\mathrm{N}-\mathrm{OH}}\right)$ orbital of $\mathrm{HNO}_{3}$. These single-bond resonances are located at lower energies than the bands at 412.3(536.2) eV and $417.0(542.5) \mathrm{eV}$ at the $\mathrm{N}(\mathrm{O}) \mathrm{K}$-edge of $\mathrm{HNO}_{3}$, attributed to transitions to its $16 \mathrm{a}^{\prime}$ and $5 \mathrm{a}^{\prime \prime}\left(\sigma^{*}{ }_{\mathrm{N}-\mathrm{O}}\right.$ and $\left.\sigma^{*}{ }_{\mathrm{N}=\mathrm{O}}\right)$ molecular orbitals. This reflects the fact that the covalent $\mathrm{N}-\mathrm{OH}$ bond in $\mathrm{HNO}_{3}$ is weaker and longer than the two other NO bonds, thereby lowering its $\sigma^{*}$ orbital energy. ${ }^{53}$ In the proton-transfer reaction leading to $\mathrm{NO}_{3}{ }^{-}{ }_{(\mathrm{aq})}$, this bond acquires more double bond character, it shortens, and its $\sigma^{*}$ orbital shifts to higher energy, merging with the other broad $\sigma^{*}{ }_{\mathrm{N}-\mathrm{O}}$ bands in the $\mathrm{N} \mathrm{K}$ edge spectrum of $\mathrm{NO}_{3}{ }^{-}$.

Therefore, investigating the extent of the ionic dissociation of $\mathrm{HNO}_{3}$ adsorbed onto ice using NEXAFS is particularly convenient given that several spectral features exist for molecular nitric acid that are quite distinct from those of nitrates. Clearly, the $404.7(531.8) \mathrm{eV}$ bands at the $\mathrm{N}(\mathrm{O}) \mathrm{K}$ edges display contributions from both $\mathrm{HNO}_{3}$ and $\mathrm{NO}_{3}{ }^{-}$and thus can unfortunately not provide information about their individual relative abundances. Unfortunately, while quite distinctive, the small peaks at 533.7 and $536.2 \mathrm{eV}$, labeled respectively $14 \mathrm{a}^{\prime}\left(\sigma_{\mathrm{NO}-\mathrm{H}}^{*}\right)$ and $15 \mathrm{a}^{\prime}\left(\sigma_{\mathrm{N}-\mathrm{OH}}^{*}\right)$, observed in the O K-edge NEXAFS spectra (Figure 1d) appear in a spectral range rather congested by strong features due to the aqueous component of the mixture (Figure 1b). This renders investigations of ionic dissociation of adsorbed $\mathrm{HNO}_{3}$ using NEXAFS spectra at the O K-edge impractical. However, while the weak spectral feature arising from transitions to the $14 \mathrm{a}^{\prime}$ $\left(\sigma^{*}{ }_{\mathrm{NO}-\mathrm{H}}\right)$ orbital is very distinctive of the molecular form of $\mathrm{HNO}_{3}$, it is extremely weak in $\mathrm{N}$ K-edge NEXAFS spectra, owing to the fact that transitions from the $\mathrm{N}(1 \mathrm{~s})$ orbital are bound to be exceedingly improbable due to its poor overlap with the $14 \mathrm{a}^{\prime}$ orbital. However, the strong band centered near $409.0 \mathrm{eV}$, which we attributed to transitions to the $15 \mathrm{a}^{\prime}$ $\left(\sigma^{*}{ }_{\mathrm{N}-\mathrm{OH}}\right)$ molecular orbital, appears in a region of the $\mathrm{N} \mathrm{K}$ edge NEXAFS spectra exempt from interference from the aqueous component of the mixture. Furthermore, as this feature does not overlap significantly with the spectral features of $\mathrm{NO}_{3}{ }^{-}$(aq) (Figure 1a), it can most clearly signal the presence of molecular nitric acid, even in the presence of nitrates resulting from partial dissociative adsorption of the adsorbate at the ice surface, thereby disclosing the extent to which $\mathrm{HNO}_{3}$ dissociates upon adsorption onto ice.

Having thus identified those spectral features distinctive to molecular $\mathrm{HNO}_{3}$, we set out to investigate nitric acid adsorption and ionic dissociation onto dense ASW as a function of coverage and temperature. The N K-edge NEXAFS spectra of $\mathrm{HNO}_{3}$ adsorbed at the surface of the ASW films are displayed in Figure 2 as a function of cumulative $\mathrm{HNO}_{3}$

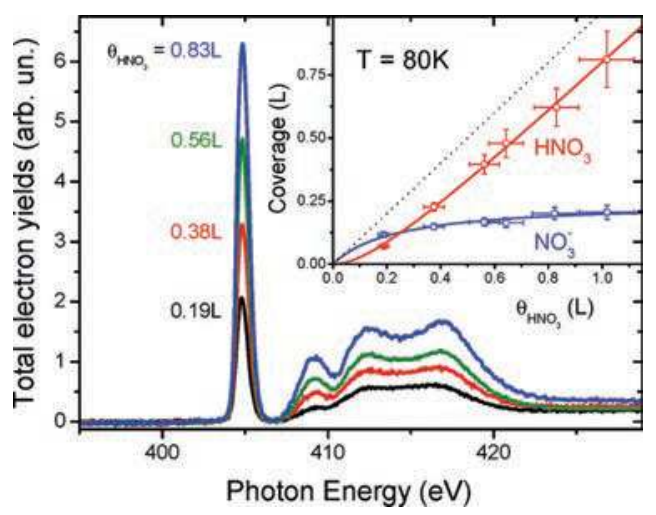

Figure 2. Nitrogen K-edge NEXAFS spectra for $\mathrm{HNO}_{3}$ deposited onto dense ASW for various cumulative nitric acid exposures, $80 \mathrm{~K}$. (Inset) $\mathrm{NO}_{3}{ }^{-}$(ads) and $\mathrm{HNO}_{3(\mathrm{ads})}$ coverages, obtained using a spectral decomposition procedure (see the SI) as a function of nitric acid exposure. The saturation coverage is determined to be $\theta_{\text {Saturation }}=0.25$ $\mathrm{L}$ for the dissociative adsorption of $\mathrm{HNO}_{3}$ onto amorphous ice at 80 $\mathrm{K}$. The continuous lines are fits to the Langmuir isotherm, while the dotted line indicates the total coverage.

exposures, $\theta_{\mathrm{HNO} 3}$, from 0.19 to $0.83 \mathrm{~L}$. All experiments were conducted on a $100 \mathrm{~L}$ coverage dense ASW film, deposited at $90 \mathrm{~K}$, while subsequent $\mathrm{HNO}_{3}$ exposures were performed at a substrate temperature of $80 \mathrm{~K}$. Each NEXAFS spectrum was recorded at the base temperature of $23 \mathrm{~K}$ and at a previously unirradiated spot (see SI for details). While the amplitude of all of the spectral features grows steadily with increasing cumulative $\mathrm{HNO}_{3}$ coverage, their relative intensities vary somewhat, suggesting that the relative abundance of nitric acid and nitrates evolves as a function of increasing $\theta_{\mathrm{HNO} 3}$. At the $\mathrm{O}$ K-edge (SI Figure S1), the NEXAFS spectra are dominated by contributions from the underlying water ice (Figure 1b). Nevertheless, the sharp pre-edge feature located near $531.8 \mathrm{eV}$, which arises from the strongly overlapping transitions to the $2 a_{2}{ }^{\prime \prime}\left(\pi^{*}\right)$ and $4 a^{\prime \prime}\left(\pi^{*}\right)$ LUMO orbitals of $\mathrm{NO}_{3}{ }^{-}$and $\mathrm{HNO}_{3}$, respectively, grows steadily with nitric acid exposure conjointly with a slight decrease of water ice absorption signal.

The relative contributions from nitrates and molecular nitric acid to the $\mathrm{N}$ K-edge NEXAFS spectrum for the various cumulative $\mathrm{HNO}_{3}$ coverages were quantified using a simple least-squares spectral decomposition procedure (SI Figure S2). This straightforward analysis yielded the relative coverages for $\mathrm{NO}_{3}{ }^{-}$(ads) (blue symbols) and for $\mathrm{HNO}_{3(\mathrm{ads})}$ (red symbols), which are reported in the inset to Figure 2, as a function of cumulative $\mathrm{HNO}_{3}$ exposure, $\theta_{\mathrm{HNO}}$, onto dense ASW at $80 \mathrm{~K}$. Continuous lines are fits to the data using a Langmuir adsorption isotherm. From data presented in Figure 2, it appears that dissociative adsorption of $\mathrm{HNO}_{3}$ at the ASW surface at $80 \mathrm{~K}$, indicated by the contribution from nitrates to the $\mathrm{N}$ K-edge NEXAFS spectra, saturates at a coverage of 0.25 $\mathrm{L}$ and that multilayer molecular nitric acid condensation proceeds thereafter with further increases in $\mathrm{HNO}_{3}$ exposure.

We verified that the sticking coefficient of $\mathrm{HNO}_{3}$ onto ASW at $T<100 \mathrm{~K}$ is unity using an effusive beam and therefore estimate that a nitric acid exposure of $0.25 \mathrm{~L}$ corresponds to an adsorbate areal density of $\sim 1.3 \times 10^{14} \mathrm{~mol} / \mathrm{cm}^{2}$ using kinetic 
theory. This areal density compares rather well with the $\mathrm{HNO}_{3}$ uptakes of $(2.9-0.7) \times 10^{14} \mathrm{~mol} / \mathrm{cm}^{2}$ by ice reported using coated-wall flow tube (CWFT) techniques by Abbatt ${ }^{54}$ in the 208-248 $\mathrm{K}$ range at a $\mathrm{HNO}_{3(\mathrm{~g})}$ partial pressure of (6-9) $\times$ $10^{-7}$ Torr. Taking into account the coupled kinetics for adsorption, desorption, and diffusion, the saturation coverage for $\mathrm{HNO}_{3}$ on ice was confirmed, on the basis of recent CWFT investigations, ${ }^{55,56}$ to lie in the $(2-3) \times 10^{14} \mathrm{~mol} / \mathrm{cm}^{2}$ range and to display only a weak temperature dependence throughout the 214-239 $\mathrm{K}$ range. ${ }^{55,56}$ Most recently, Marchand et al. ${ }^{12}$ reported that $\sim 75(90) \%$ of the $\mathrm{HNO}_{3}$ adsorbates ionically dissociated upon adsorption onto dense ASW at $45 \mathrm{~K}(80 \mathrm{~K})$ based on infrared spectroscopy (corresponding to $\sim 3.5(4.0) \times$ $10^{14} \mathrm{~mol} / \mathrm{cm}^{2}$ saturation coverage for dissociative adsorption of $\mathrm{HNO}_{3}$ ). One should however exert caution in concluding to a possible increase in the saturation coverage for dissociated nitric acid on ice with decreasing temperatures as this limited set of data used widely different partial $\mathrm{H}_{2} \mathrm{O}$ and $\mathrm{HNO}_{3}$ vapor pressures, as well as different ice substrates (microporous versus dense ASW, polycrystalline ice, etc.). For a recent critical review of heterogeneous kinetic data up to 2010, including interactions of nitric acid and ice, see Crowley et al. ${ }^{57}$

The temperature dependence of the ionic dissociation of $\mathrm{HNO}_{3}$ adsorbed onto ASW was also investigated. The N Kedge NEXAFS spectrum for a sample composed of a $100 \mathrm{~L}$ coverage dense ASW deposited at $90 \mathrm{~K}$ onto which $\theta_{\mathrm{HNO} 3}=$ $0.37 \mathrm{~L}$ was dosed at $23 \mathrm{~K}$ is displayed as a black trace in Figure 3 (i.e., bottom spectrum). The sample was then annealed at

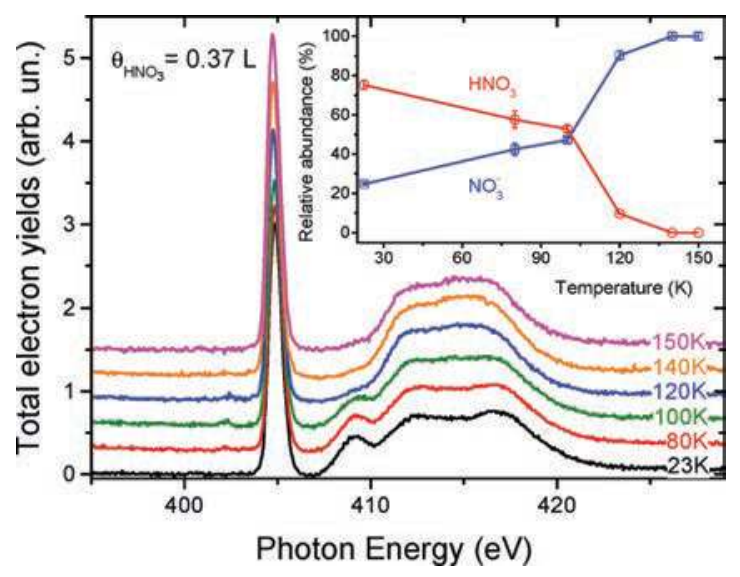

Figure 3. Nitrogen K-edge NEXAFS spectra for a nitric acid coverage of $\theta_{\mathrm{HNO} 3}=0.37 \mathrm{~L}$, deposited onto ASW at $23 \mathrm{~K}$ and annealed at various temperatures. All spectra were acquired at $23 \mathrm{~K}$ and are offset vertically for clarity. (Inset) Relative abundances for $\mathrm{NO}_{3}{ }^{-}$(ads) and

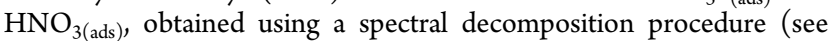
the $\mathrm{SI}$ ) as a function of annealing temperature.

various temperatures for $5 \mathrm{~min}$, and it was then cooled back to the base temperature (i.e., $23 \mathrm{~K}$ ) where its $\mathrm{N}$ K-edge NEXAFS spectrum was recorded at a previously unirradiated spot. The resulting spectrum is color-coded to the corresponding annealing temperature and is vertically offset for clarity in Figure 3. The most outstanding feature displayed by this series of NEXAFS spectra is the sudden disappearance of the band located at $409.0 \mathrm{eV}$, attributed to transitions to the $15 \mathrm{a}^{\prime}$ $\left(\sigma^{*}{ }_{\mathrm{N}-\mathrm{OH}}\right)$ molecular orbital of $\mathrm{HNO}_{3}$, signaling the dissociation of adsorbed $\mathrm{HNO}_{3}$ upon annealing above $100 \mathrm{~K}$.

A spectral decomposition scheme similar to that employed to analyze the NEXAFS spectra as a function of nitric acid coverage (i.e., Figure 2 and SI Figure S2) was therefore used to extract the relative abundances of $\mathrm{NO}_{3}^{-}$(ads) and $\mathrm{HNO}_{3(\mathrm{ads})}$ from their individual contributions to the $\mathrm{N}$ K-edge NEXAFS spectra of $0.37 \mathrm{~L} \mathrm{HNO}_{3}$ adsorbed onto ice (SI Figure S3). The evolution of the relative abundances is reported as a function of annealing temperature in the inset to Figure 3. The sudden decrease in the relative abundance of $\mathrm{HNO}_{3(\mathrm{ads})}$ and the concomitant increase in the relative abundance of $\mathrm{NO}_{3}{ }^{-}$(ads) reveal extensive and irreversible dissociation of nitric acid adsorbed onto ice upon annealing above $100 \mathrm{~K}$.

At the nitric acid coverage of this experiment, $\theta_{\mathrm{HNO} 3}=0.37$ L, $25 \%$ of the adsorbates appear to ionically dissociate upon adsorbing onto ice at $23 \mathrm{~K}$, indicating that a significant fraction of $\mathrm{HNO}_{3}$ dissociates spontaneously upon adsorbing onto the ice surface, even down to $23 \mathrm{~K}$. However, this coverage exceeds the saturation coverage, determined as $0.25 \mathrm{~L}$ for $\mathrm{HNO}_{3}$ on ice at $80 \mathrm{~K}$, by $\sim 50 \%$, thereby providing a rational for the relatively high abundance of molecularly adsorbed $\mathrm{HNO}_{3}$ on ice observed at $23 \mathrm{~K}$.

Upon annealing up to 80 and $100 \mathrm{~K}$, the relative abundances of nitrates increase and that of molecular nitric acid decreases, their ratio evolving to reflect the saturation coverage for dissociative adsorption determined for dense ASW at $80 \mathrm{~K}$ (i.e., $\sim 60: 40$ as seen in the inset to Figure 2). As the temperature increases further to 120,140 , and finally $150 \mathrm{~K}$, diffusion and bulk uptake must progressively set in, thereby allowing extensive dissociation and dissolution of the excess molecularly adsorbed $\mathrm{HNO}_{3 \text { (ads) }}$ overlayer. This must therefore signal the onset of thermally activated intermixing at the $\mathrm{H}_{2} \mathrm{O} / \mathrm{HNO}_{3}$ interface similarly to what was reported by Pursell et al. for molecularly adsorbed nitric acid multilayers onto crystalline ice. ${ }^{13}$ The spatial extent of intermixing cannot be determined from NEXAFS data alone however; the fact that the raw integrated intensity at the $\mathrm{N}$ K-edge does not diminish significantly with increasing temperature indicates that intermixing does not extend beyond the electron inelastic mean free path (i.e., $\leq 50 \AA$ ) ${ }^{9,10}$ More importantly, however, the progressive and irreversible dissociation of $\mathrm{HNO}_{3}$ adsorbed onto ice upon annealing up to $100 \mathrm{~K}$ suggests that molecularly adsorbed nitric acid is metastable at the surface of ice.

To summarize, this spectroscopic study of the adsorption of nitric acid onto ASW identified distinctive NEXAFS features at the $\mathrm{N}$ and $\mathrm{O}$ K-edges for molecularly adsorbed nitric acid,

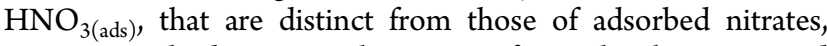
$\mathrm{NO}_{3}{ }^{-}$(ads). The key spectral signature for molecular nitric acid identification was a band located at $409.0 \mathrm{eV}$ at the $\mathrm{N}$ K-edge, a feature that was assigned to transitions to the $15 \mathrm{a}^{\prime}\left(\sigma_{\mathrm{N}-\mathrm{OH}}\right)$ molecular orbital of $\mathrm{HNO}_{3}$. This enabled one to clearly establish and accurately quantify the extent of nitric acid dissociation as a function of coverage and temperature. While ionic dissociation of $\mathrm{HNO}_{3}$ upon adsorption onto ASW was found to be spontaneous down to $23 \mathrm{~K}$, some metastable, molecularly adsorbed $\mathrm{HNO}_{3}$ could also be trapped, either at the surface of ice at temperatures below $100 \mathrm{~K}$ or at nitric acid coverages exceeding the dissociative adsorption saturation coverage, $\theta_{\mathrm{HNO} 3}=0.25 \mathrm{~L}$ or $\sim 1.3 \times 10^{14} \mathrm{~mol} / \mathrm{cm}^{2}$.

Those findings indicate that the propensity for nitric acid to be extensively dissociated in aqueous solutions, and even down to the supercooled regime, is preserved upon adsorption onto amorphous ice at cryogenic temperatures. Indeed, acid-base thermodynamics of aqueous nitric acid solutions indicate a very strong exothermic character for ionic dissociation of $\mathrm{HNO}_{3}$ in water at ambient temperature and pressure. ${ }^{32}$ This strong 
enthalpic driving force is also counteracted by a substantial entropic inhibition, ${ }^{32}$ as described previously in a study of cryogenic hydrofluoric acid solutions. ${ }^{58}$ At lower temperatures, such as those of the polar boundary layer, the troposphere, and the lower stratosphere, the strongly exothermic character for the dissociative adsorption of $\mathrm{HNO}_{3}$ could very well overwhelm the slight decrease in its acidity reported to occur at the surface of aqueous solutions. In the temperature and concentration regimes relevant to environmental chemistry processes, our findings strongly suggest that nitric acid should mostly exist in its dissociated form, the lifetime of molecularly adsorbed $\mathrm{HNO}_{3}$ being recently reported to be subpicoseconds, ${ }^{6}$ when adsorbed onto wet particulate matter or supercooled aerosols, as well as at the surface of the quasi-liquid layer that exists at the surface of snowflakes or ice crystals in the atmosphere below the normal melting point of ice.

\section{ASSOCIATED CONTENT}

\section{S Supporting Information}

Details of the sample preparation protocols, the oxygen K-edge NEXAFS spectra recorded as a function of nitric acid exposure, which correspond to the nitrogen K-edge spectra reported in Figure 2, as well as the details of the spectral decomposition analysis of the NEXAFS $\mathrm{N}$ K-edge spectra for $\mathrm{HNO}_{3}$ adsorption as a function of nitric acid exposure (Figure 2) and annealing temperature (Figure 3). This material is available free of charge via the Internet at http://pubs.acs.org.

\section{AUTHOR INFORMATION}

\section{Corresponding Author}

*E-mail: patrick.ayotte@usherbrooke.ca. Tel.:819-821-7889. Fax: 819-821-8017 (P.A.); E-mail: parent@cinam.univ-mrs.fr. Tel: +33(0)6 603028 07. Fax: +33(0)4 91418916 (P.P.).

\section{Notes}

The authors declare no competing financial interest.

\section{ACKNOWLEDGMENTS}

We thank the SOLEIL synchrotron facility for providing installations (project No. 20110861). In particular, we thank $\mathrm{Ch}$. Chauvet for his technical support at the TEMPO beamline. We are also grateful to NSERC (Canada) and CNRS (France) for financial support for this work. G.M. thanks FQRNT and EGIDE for doctoral fellowships. P.A., P.P., and C.L. wish to acknowledge $63^{\mathrm{e}}$ CPCFQ for support. P.P. and C.L. acknowledge support from PICS-CNRS, Project 06212. P.A. thanks the staff of the Laboratoire de Chimie Physique - Matière et Rayonnement (Université Pierre et Marie Curie, Paris VI) for their hospitality as well as UPMC and Université de Sherbrooke for support during his sabbatical stay.

\section{REFERENCES}

(1) Shamay, E. S.; Buch, V.; Parrinello, M.; Richmond, G. L. At the Water's Edge: Nitric Acid As a Weak Acid. J. Am. Chem. Soc. 2007, 129, 12910-12911.

(2) Bianco, R.; Wang, S.; Hynes, J. T. Infrared Signatures of $\mathrm{HNO}_{3}$ and $\mathrm{NO}_{3}{ }^{-}$at a Model Aqueous Surface. A Theoretical Study. J. Phys. Chem. A 2008, 112, 9467-9476.

(3) Wang, S.; Bianco, R.; Hynes, J. T. Dissociation of Nitric Acid at an Aqueous Surface: Large Amplitude Motions in the Contact Ion Pair to Solvent-Separated Ion Pair Conversion. Phys. Chem. Chem. Phys. 2010, 12, 8241-8249.
(4) Wang, S.; Bianco, R.; Hynes, J. T. Nitric Acid Dissociation at an Aqueous Surface: Occurence and Mechanism. Isr. J. Chem. 2009, 49, 251-259.

(5) Miller, Y.; Gerber, R. B. Dynamics of Proton Recombination with $\mathrm{NO}_{3}{ }^{-}$Anion in Water Clusters. Phys. Chem. Chem. Phys. 2008, 10, 1091-1093.

(6) Riikonen, S.; Parkkinene, P.; Halonen, L.; Gerber, B. R. Ultrafast Ionization of Nitric Acid on Crystalline Ice: The Role of Defects. J. Phys. Chem. Lett. 2013, 4, 1850-1855.

(7) Ramazan, K. A.; Wingen, L. M.; Miller, Y.; Chaban, G. M.; Gerber, R. B.; Xantheas, S. S.; Finlayson-Pitts, B. J. New Experimental and Theoretical Approach to the Heterogeneous Hydrolysis of $\mathrm{NO}_{2}$ : Key Role of Molecular Nitric Acid and Its Complexes. J. Phys. Chem. 2006, 110, 6886-6897.

(8) Kido Soule, M. C.; Blower, P. G.; Richmond, G. L. Nonlinear Vibrational Spectroscopic Studies of the Adsorption and Speciation of Nitric Acid at the Vapor/Acid Solution Interface. J. Phys. Chem. A 2007, 111, 3349-3357.

(9) Lewis, T.; Winter, B.; Stern, A. C.; Baer, M. D.; Mundy, C .J.; Tobias, D. J.; Hemminger, J. C. Dissociation of Strong Acid Revisited: X-ray Photoelectron Spectroscopy and Molecular Dynamics Simulations of $\mathrm{HNO}_{3}$ in Water. J. Phys. Chem. B 2011, 115, 9445-9451.

(10) Lewis, T.; Winter, B.; Stern, A. C.; Baer, M. D.; Mundy, C. J.; Tobias, D. J.; Hemminger, J. C. Does Nitric Acid Dissociate at the Aqueous Solution Surface? J. Phys. Chem. C 2011, 115, 21183-21190.

(11) Yang, H.; Finlayson-Pitts, B. J. Infrared Spectroscopic Studies of Binary Solutions of Nitric Acid and Water and Ternary Solutions of Nitric Acid, Sulfuric Acid, and Water at Room Temperature: Evidence for Molecular Nitric Acid at the Surface. J. Phys. Chem. A 2001, 105, 1890-1896.

(12) Marchand, P.; Marcotte, G.; Ayotte, P. Spectroscopic sStudy of $\mathrm{HNO}_{3}$ Dissociation on Ice. J. Phys. Chem. A 2012, 116, 12112-12122.

(13) Pursell, C. J.; Everest, M. A.; Falgout, M. E.; Sanchez, D. D. Ionization of Nitric Acid on Ice. J. Phys. Chem. A 2002, 106, 77647768 .

(14) Devlin, J.; Uras, N.; Rahman, M.; Buch, V. Covalent and Ionic States of Strong Acids at the Ice Surface. Isr. J. Chem. 1999, 39, 261272.

(15) Finlayson-Pitts, B. J. Reactions at Surfaces in the Atmosphere: Integration of Experiments and Theory As Necessary (But Not Necessarily Sufficient) for Prediction the Physical Chemistry of Aerosols. Phys. Chem. Chem. Phys. 2009, 11, 7760-7779.

(16) Goodman, A. L.; Bernard, E. T.; Grassian, V. H. Spectroscopic Study of Nitric Acid and Water Adsorption on Oxide Particles: Enhanced Nitric Acid Uptake Kinetics in the Presence of Adsorbed Water. J. Phys. Chem. A 2001, 105, 6443-6457.

(17) Gibson, E. R.; Hudson, P. K.; Grassian, V. H. Physicochemical Properties of Nitrate Aerosols: Implications for the Atmosphere. J. Phys. Chem. A 2006, 110, 11785-11799.

(18) Al-Hosney, H. A.; Grassian, V. H. Water, Sulfur Dioxide and Nitric Acid Adsorption on Calcium Carbonate: A Transmission and ATR-FTIR Study. Phys. Chem. Chem. Phys. 2005, 7, 1266-1276.

(19) Laskin, A.; Wietsma, T. W.; Krueger, B. J.; Grassian, V. H. Heterogeneous Chemistry of Individual Mineral Dust Particles with Nitric Acid: A Combined CCSEM/EDX, ESEM, and ICP-MS Study. J. Geophys. Res. 2005, 110, D10208/1-D10208/15.

(20) Beine, H. J.; Domine, F.; Ianniello, A.; Nardino, M.; Allegrini, I.; Teinilae, K.; Hillamo, R. Fluxes of Nitrates between Snow Surfaces and the Atmosphere in the European High Arctic. Atmos. Chem. Phys. 2003, 3, 335-346.

(21) Morin, S.; Savarino, J.; Frey, M. M.; Yan, N.; Bekki, S.; Bottenheim, J. W.; Martins, J. M. F. Tracing the Origin and Fate of $\mathrm{NO}_{\mathrm{x}}$ in the Arctic Atmosphere Using Stable Isotopes in Nitrate. Science 2008, 322, 730-732.

(22) Jones, A. E.; et al. The Multi-Seasonal $\mathrm{NO}_{\mathrm{y}}$ Budget in Coastal Antarctica and Its Link with Surface Snow and Ice Core Nitrate: Results from the CHABLIS Campaign. Atmos. Chem. Phys. 2011, 11, 9271-9285. 
(23) Kamboures, M. A.; Raff, J. D.; Miller, Y.; Phillips, L. F.; Finlayson-Pitts, B. J.; Gerber, R. B. Complexes of $\mathrm{HNO}_{3}$ and $\mathrm{NO}_{3}{ }^{-}$ with $\mathrm{NO}_{2}$ and $\mathrm{N}_{2} \mathrm{O}_{4}$, and Their Potential Role in Atmospheric HONO Formation. Phys. Chem. Chem. Phys. 2008, 10, 6019-6032.

(24) Grannas, A. M.; et al. An Overview of Snow Photochemistry: Evidence, Mechanisms and Impacts. Atmos. Chem. Phys. 2007, 7, 4329-4373.

(25) Domine, F.; Shepson, P. B. Air-Snow Interactions and Atmospheric Chemistry. Science 2002, 297, 1506-1510.

(26) Jacobi, H.-W.; Hilker, B. A Mechanism for the Photochemical Transformation of Nitrate in Snow. J. Photochem. Photobiol., A 2007, 185, 371-382.

(27) Minogue, N.; Riordan, E.; Sodeau, J. R. Raman Spectroscopy as a Probe of Low-Temperature Ionic Speciation in Nitric and Sulfuric Acid Stratospheric Mimic Systems. J. Phys. Chem A 2003, 107, 44364444.

(28) Voigt, C.; et al. Nitric Acid in Cirrus Clouds. Geophys. Res. Lett. 2006, 33, L05803/1-L05803/4.

(29) Voigt, C.; et al. In-Situ Observations and Modeling of Small Nitric Acid-Containing Ice Crystals. Atmos. Chem. Phys 2007, 7, $3373-3383$.

(30) Kinnison, D. E.; et al. Global Observations of $\mathrm{HNO}_{3}$ from the High Resolution Dynamics Limb Sounder (HIRDLS): First Results. J. Geophys. Res. 2008, 113, D16S44/1-D16s44/21.

(31) Hayden, K. L.; Macdonald, A. M.; Gong, W.; Toom-Sauntry, D.; Anlauf, K. G.; Leithead, A.; Li, S. M.; Leaitch, W. R.; Noone, K. Cloud Processing of Nitrate. J. Geophys. Res. 2008, 113, D18201/1-D18201/ 18.

(32) Christensen, J. J.; Hansen, L. D.; Izatt, R. M. Handbook of Proton Ionizaion Heats and Related Thermodynamis Quantities; John Wiley \& Sons: New York, 1976.

(33) Ardura, D.; Donaldson, D. J. Where Does Acid Hydrolysis Take Place? Phys. Chem. Chem. Phys. 2009, 11, 857-863.

(34) Zondlo, M. A.; Barone, S. B.; Tolbert, M. A. Experimental Studies of Vapor-Deposited Water-Ice Films Using Grazing-Angle FTIR-Reflection Absorption Spectroscopy. Geophys. Res. Lett. 1997, 24, 1391-1394.

(35) Krepelova, A.; Newberg, J.; Huthwelker, T.; Bluhm, H.; Ammann, M. The Nature of Nitrate at the Ice Surface Studied by XPS and NEXAFS. Phys. Chem. Chem. Phys. 2010, 12, 8870-8880.

(36) Angell, C. A. Insights into Phases of Liquid Water from Study of Its Unusual Glass-Forming Properties. Science 2008, 319, 582-587.

(37) Smith, R. S.; Dohnalek, Z.; Kimmel, G. A.; Stevenson, K. P.; Kay, B. D. The Self-Diffusivity of Amorphous Solid Water Near $150 \mathrm{~K}$. Chem. Phys. 2000, 258, 291-305.

(38) Salvador, P.; Curtis, J. E.; Tobias, D. J.; Jungwirth, P. Polarizability of the Nitrate Anion and Its Solvation at the Air/ Water Interface. Phys. Chem. Chem. Phys. 2003, 5, 3752-3757.

(39) Dang, L. X.; Chang, T.-M.; Roeselova, M.; Garrett, B. C.; Tobias, D. J. On $\mathrm{NO}_{3}-\mathrm{H}_{2} \mathrm{O}$ Interactions in Aqueous Solutions and at Interfaces. J. Chem. Phys. 2006, 124, 066101/1-066101/3.

(40) Xu, M.; Spinney, R.; Allen, H. C. Structure at the Air-Aqueous Interface of Divalent Cation and Nitrate Solutions. J. Phys. Chem. B 2009, 113, 4102-4110.

(41) Otten, D. E.; Petersen, P. B.; Saykally, R. J. Observation of Nitrate Ions at the Air/Water Interface by UV-Second Harmonic Generation. Chem. Phys. Lett. 2007, 449, 261-265.

(42) Petersen, P. B.; Saykally, R. J. Adsorption of Ions to the Surface of Dilute Electrolyte Solutions: The Jones-Ray Effect Revisited. J. Am. Chem. Soc. 2005, 127, 15446-15452.

(43) Petersen, P. B.; Saykally, R. J. On the Nature of Ions at the Liquid Water Surface. Annu. Rev. Phys. Chem. 2006, 57, 333-364.

(44) Buch, V.; Milet, A.; Vacha, R.; Jungwith, P.; Devlin, J. P. Water Surface Is Acidic. Proc. Natl. Acad. Sci. U.S.A. 2007, 140, 7342-7437.

(45) Szanyi, J.; Hun Kwak, J.; Burton, S.; Rodriguez, J. A.; Peden, C. H. F. Characterization of $\mathrm{NO}_{\mathrm{x}}$ Species in Dehydrated and Hydrated Na- and Ba-Y, FAU Zeolites Formed in $\mathrm{NO}_{2}$ Adsorption. J. Electron Spectrosc. Relat. Phenom. 2006, 150, 164-170.
(46) Koch, T. G.; Holmes, N. S.; Roddis, T. B.; Sodeau, J. R. A LowTemperature Reflection-Absorption Infrared Spectroscopic Study of Ultrathin Films of Dinitrogen Tetroxide and Dinitrogen Pentoxide on Gold Foil. J. Phys. Chem. 1996, 100, 11402-11407.

(47) Preobrajenski, A. B.; Vinogradov, A. S.; Molodtsov, S. L.; Krasnikov, S. A.; Chassé, T.; Szargan, R.; Laubschat, C. Molecular Effects in Solid $\mathrm{NaNO}_{3}$ Observed by X-ray Absorption and Resonant Auger Spectroscopy. Phys. Rev. B 2002, 65, 205116/1-205116/10.

(48) Preobrajenski, A. B.; Vinogradov, A. S.; Molodtsov, S. L.; Krasnikov, S. A.; Szargan, R.; Laubschat, C. Resonant Auger Spectroscopy in Solid Alkali Nitrates As a Probe of Nuclear Motion in the Core-Excited $\mathrm{NO}_{3}{ }^{-}$Anion. Chem. Phys. Lett. 2003, 368, 125131.

(49) Sivkov, V. N.; Vinogradov, A. S.; Nekipelov, S. V.; Sivkov, D. V.; Vyalykh, D. V.; Molodtsov, S. L. Oscillator Strengths for the Shape Resonances in the $\mathrm{N} \mathrm{K}$ Absorption Spectrum of $\mathrm{NaNO}_{3}$ Measured with the Use of Synchrotron Radiation. Opt. Spectrosc. 2006, 101, 724-730.

(50) Frisch, M. J.; et al. Gaussian 03, revision E.01; Gaussian, Inc.: Wallingford, CT, 2004.

(51) Brown, M. A.; Winter, B.; Faubel, M.; Hemminger, J. C. Spatial Distribution of Nitrate and Nitrite Anions at the Liquid/Vapor Interface of Aqueous Solutions. J. Am. Chem. Soc. 2009, 131, 83548355.

(52) Parent, Ph.; Laffon, C.; Mangeney, C.; Bournel, F.; Tronc, M. Structure of the Water Ice Surface Studied by X-ray Absorption Spectroscopy at the O K-Edge. J. Chem. Phys. 2002, 23, 10842-10851.

(53) Stöhr, J.; Sette, F.; Johnson, A. L. Near-Edge X-ray-Absorption Fine Structure Studies of Chemisorbed Hydrocarbons: Bond Lenghts with a Ruler. Phys. Rev. Lett. 1984, 53, 1684-1687.

(54) Abbatt, J. P. D. Interaction of $\mathrm{HNO}_{3}$ with Water-Ice Surfaces at Temperatures of the Free Troposphere. Geophys. Res. Lett. 1997, 24, $1479-1482$.

(55) Ullerstam, M.; Abbatt, J. P. D. Burial of Gas-Phase $\mathrm{HNO}_{3}$ by Growing Ice Surfaces under Tropospheric Conditions. Phys. Chem. Chem. Phys. 2005, 7, 3596-3600.

(56) Cox, R. A.; Fernandez, M.; Symington, A.; Ullerstam, M.; Abbatt, J. P. D. A Kinetic Model for Uptake of $\mathrm{HNO}_{3}$ and $\mathrm{HCl}$ on Ice in a Coated Wall Flow System. Phys. Chem. Chem. Phys. 2005, 7, 3434-3442.

(57) Crowley, J. N.; Ammann, M.; Cox, R. A.; Hynes, R. G.; Jenkin, M. E.; Mellouki, A.; Rossi, M. J.; Troe, J.; Wallington, T. J. Evaluated Kinetic and Photochemical Data for Atmospheric Chemistry: Volume $\mathrm{V}$ - Heterogeneous Reactions on Solid Substrates. Atmos. Chem. Phys. 2010, 10, 9059-9223.

(58) Ayotte, P.; Hébert, M.; Marchand, P. Why is Hydrofluoric Acid a Weak Acid ? J. Chem. Phys. 2005, 123, 184501/1-184501/8. 